\title{
Metagenomic Analysis of Bacterial Diversity in Traditional Fermented Foods Reveals Food-Specific Dominance of Specific Bacterial Taxa
}

\author{
Purbajyoti Deka ${ }^{1}$, Gajanan T. Mehetre ${ }^{1}$, Esther Lalnunmawii ${ }^{1}$, Kalidas Upadhyaya ${ }^{2}$, Garima Singh ${ }^{3}(1)$, \\ Abeer Hashem ${ }^{4}\left(\mathbb{D}\right.$, Al-Bandari Fahad Al-Arjani ${ }^{4}$, Elsayed Fathi Abd_Allah ${ }^{5}{ }^{(0)}$ and Bhim Pratap Singh ${ }^{1,6, *}$ (i) \\ 1 Department of Biotechnology, Mizoram University, Aizawl 796004, Mizoram, India; \\ purba562@gmail.com (P.D.); gtmehetre@gmail.com (G.T.M.); essie.zadeng@gmail.com (E.L.) \\ 2 Department of Forestry, Mizoram University, Aizawl 796004, Mizoram, India; kumzu70@gmail.com \\ 3 Department of Botany, Pachhunga University College (PUC), Mizoram University, Aizawl 796001, Mizoram, \\ India; garima.singh106@gmail.com \\ 4 Botany and Microbiology Department, College of Science, King Saud University, P.O. Box 2460, \\ Riyadh 11451, Saudi Arabia; habeer@ksu.edu.sa (A.H.); aalarjani@ksu.edu.in (A.-B.F.A.-A.) \\ 5 Plant Production Department, College of Food and Agricultural Sciences, King Saud University, \\ P.O. Box 2460, Riyadh 11451, Saudi Arabia; eabdallah@ksu.edu.sa \\ 6 Department of Agriculture and Environmental Sciences (AES), National Institute of Food Technology \\ Entrepreneurship \& Management (NIFTEM), Kundli 131028, Haryana, India \\ check for \\ * Correspondence: bhimpratap@gmail.com; Tel.: +91-943-635-3807
}

updates

Citation: Deka, P.; Mehetre, G.T.; Lalnunmawii, E.; Upadhyaya, K.; Singh, G.; Hashem, A.; Al-Arjani, A.-B.F.; Fathi Abd_Allah, E.; Singh, B.P. Metagenomic Analysis of Bacterial Diversity in Traditional Fermented Foods Reveals Food-Specific Dominance of Specific Bacterial Taxa. Fermentation 2021, 7, 167. https://doi.org/10.3390/ fermentation7030167

Academic Editor: Hiroshi Kitagaki

Received: 27 July 2021

Accepted: 21 August 2021

Published: 26 August 2021

Publisher's Note: MDPI stays neutral with regard to jurisdictional claims in published maps and institutional affiliations.

Copyright: (c) 2021 by the authors. Licensee MDPI, Basel, Switzerland. This article is an open access article distributed under the terms and conditions of the Creative Commons Attribution (CC BY) license (https:// creativecommons.org/licenses/by/ $4.0 /)$.

\begin{abstract}
Traditional fermented foods have been recognized by various communities to be good for health since ancient times. There is a provincial legacy of traditional fermented foods among the ethnic population of North-East India. Fermented bamboo shoots (local name: Tuaither), soybeans (Bekang), and pork fat (Sa-um) are famous in the Mizoram state and represent a primary portion of the daily diet. These foods are prepared using methods based on cultural traditions inherited from previous generations, and prepared using a relatively uncontrolled fermentation process. Analysis of the bacterial diversity in these foods can provide important information regarding the flavor and texture of the final products of fermentation. Unfortunately, studies on the microbial composition and health benefits of such traditional fermented foods have rarely been documented. Therefore, the present study aims to highlight this bacterial diversity, along with the proximate composition of different traditional fermented foods (Tuaither, Bekang and Sa-um) primarily consumed in Mizoram state, India. Samples were collected on three different days of fermentation (3rd, 5th and 7th day), and bacterial diversity analysis was performed using the V3-V4 variable region of $16 \mathrm{~S}$ rRNA gene with Illumina sequencing. Results revealed differences in the bacterial composition of dominant group members among all of the three food types. Firmicutes (82.72-94.00\%), followed by Proteobacteria (4.67-15.01\%), were found to dominate to varying degrees in all three of the fermented foods. However, at genus level high variation was observed in bacterial composition among these three different types of fermented foods. Lactobacillus (91.64-77.16\%), Staphylococcus (52.00-17.90\%), and Clostridium (72.48-55.40\%) exhibited the highest relative abundances in the Tuaither, Bekang and Sa-um foods, respectively, in descending order from the 3rd to 7th day of fermentation. A few of the bacterial genera such as Lactobacilli were positively correlated with fermented bamboo shoot samples, and Staphylococcus was positively correlated with protein, carbohydrate and crude fiber content in soybean samples. In general, Tuaither, Bekang and Sa-um exhibited distinct differences in bacterial composition. This variation may be due to differences in the raw materials and/or methods used in the preparation of the different fermented food products. This is the first study to describe the bacterial composition of these traditional fermented foods using high-throughput sequencing techniques, and could help to drive research attention to comprehensive studies on improving understanding of the role of microbial communities in the preparation of traditional foods and their health benefits.
\end{abstract}

Keywords: traditional fermented foods; metagenomics; bacterial diversity; health benefits; proximate analysis 


\section{Introduction}

Traditional fermented foods provide many health benefits and have been prepared by various communities around the world since ancient times. Numerous beneficial microorganisms confer unique properties to finished fermented food products through their metabolic activities. Therefore, analyzing bacterial abundance and diversity in fermented foods is important to understand the role of microbial taxa in establishing flavor and taste, along with other health benefits. Fermented foods also play a role in altering the microbial composition of the digestive tract of consumers [1]. Several previous research studies which utilized microbial culturing and identification of a particular fermented food product have reported that a few dominant microbial taxa play a major role in the fermentation process [2,3]. During the fermentation process, bacterial species convert raw food constituents into products that enhance the flavor and nutraceutical value of the final fermented product [4]. A more comprehensive understanding of microbial composition in fermented food products, however, requires an approach not limited by culture-based methods. In the past decade, culture-independent approaches utilizing polymerase chain reaction (PCR)-based amplification and sequencing of 16S rRNA genes have proven to be useful for the microbiological investigation of a variety of fermented foods [5-7]. Recent advances in next generation sequencing (NGS) technologies have provided platforms to explore microbial diversity and functionality in a variety of environments $[8,9]$. NGS techniques have been used to characterize the microbial communities of a variety of fermented foods and beverages, such as kimchi [10], kefir grains [11], Chinese rice wine [12], etc. Considering the wide variety of fermented foods in North-East India, relatively few studies, based on NGS technologies, have been conducted on fermented foods indigenous to North-East India. Previous studies have been conducted on Bekang [13], Rawtuai rep (fermented bamboo shoot) [14], and Sa-um [15], but these have been based on microbial culture methods. Therefore, microbial analysis, utilizing NGS technologies, of traditional fermented foods provincial to this region could greatly enhance our knowledge of the bacterial diversity present in these fermented products, and contribute to preserving the ethnicity of traditional indigenous fermented foods.

Fermented foods are rich in nutrients with desirable organoleptic properties and are popular due to their unique flavors [16]. The ethnic population of North-East India is among the groups that have a long history of preparing traditional fermented food products. These foods are prepared based on ethnic knowledge that has been passed down from generation to generation for thousands of years $[17,18]$. The production of these fermented foods involves natural and spontaneous fermentation. A diverse range of microbes are involved in the fermentation process, some of which contribute to the unique flavors and textures of the final products [19]. Fermented bamboo shoot (FBS) (local name: Tuaither), fermented soybean (FSB) (local name: Bekang) and fermented pork fats (FPF) (local name: Sa-um) are traditional fermented foods that are widely eaten among the peoples of the Mizoram state in North-East India. All of these food products are prepared using a natural fermentation process in a relatively uncontrolled manner. Therefore, the various microbes responsible for the fermentation may be derived from the raw materials and/or other sources, including the processing equipment, air, and water used to prepare the fermented product. In this context, analyzing microbial composition using high throughput sequencing approaches could be more beneficial for understanding the health benefits of microbes from traditional foods. The bacterial diversity and composition present in Tuaither, Bekang and Sa-um fermented foods consumed in the Mizoram state have not been investigated using metagenomics approaches.

Therefore, the objective of the present study was to characterize the bacterial diversity and nutritional composition of popular traditional fermented foods from the Mizoram state of North-East India. Sampling was done in triplicates for each of Tuaither, Bekang and Sa-um fermented foods from local markets in Mizoram at three distinct days during fermentation. Bacterial diversity, based on the 16S rRNA gene (V3-V4 region) was conducted using an IlluminaMiSeq platform with further bioinformatics analysis. Proximate 
composition such as moisture, ash, fat, protein and carbohydrate content was also analyzed for all three types (Tuaither, Bekang, and Sa-um) of fermented food samples. Furthermore, correlation analysis of the proximate parameters with the bacterial phyla and genera was also undertaken. We assumed that we would identify differences in the nutritional compounds and bacterial community composition among the samples of the three different types of food. To the best of our knowledge, this is the first report that has investigated the microbial diversity and proximate nutritional composition of traditional fermented food from the Mizoram state of North-East India.

\section{Materials and Methods}

\subsection{Collection of Food Samples}

Three different types of fermented food products native to the Mizoram state of NorthEast India were sampled in triplicates. Tuaither (prepared using bamboo shoots), Bekang (prepared using soybean), and Sa-um (prepared using pork fat) are all widely-prepared and consumed by local communities (Figure 1).

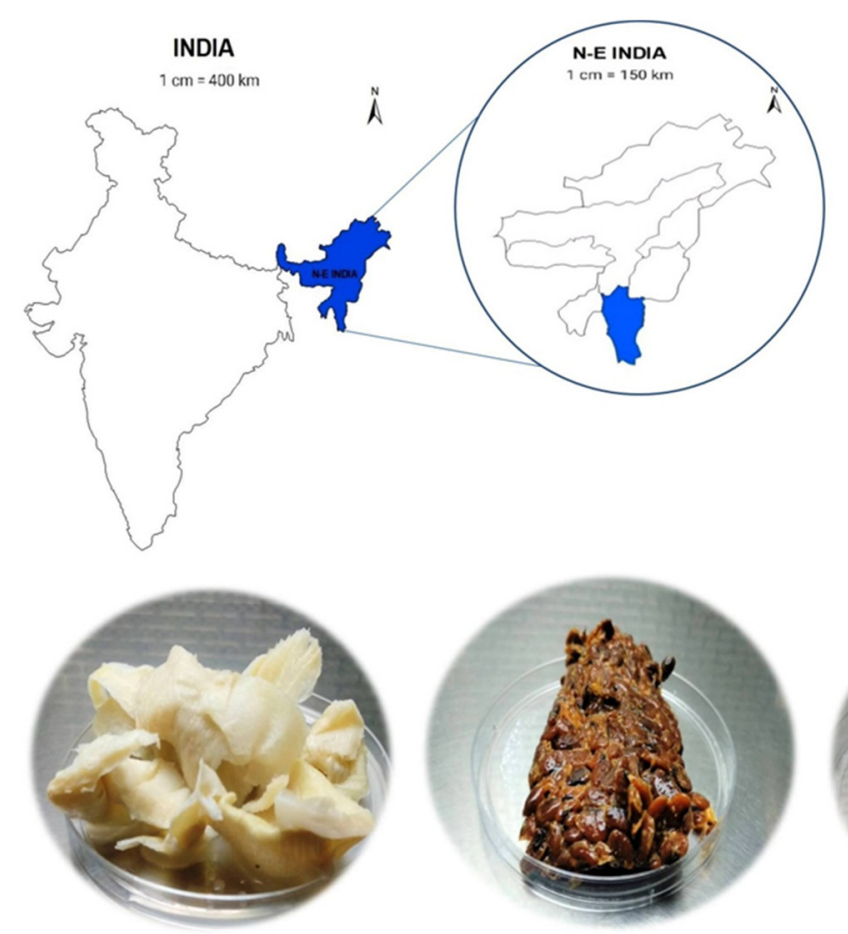

(a) Fermented bamboo shoots (Tuaither) (b) Fermented soybean (Bekang)

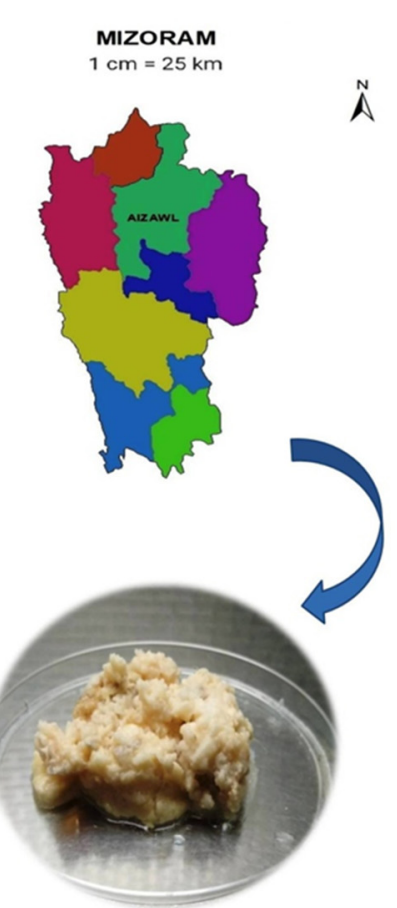

(c) Fermented pork fats (Sa-um)

Figure 1. Maps indicating the sampling location in Aizawl in the Mizoram state of North-East India, as well as representative photographs of Tuaither (a), Bekang (b) and Sa-um (c) fermented foods produced and consumed by the local community.

These food products are prepared using traditional methods of processing involving spontaneous fermentation, as has been conducted since ancient times. The samples were collected from local vendors in the Aizawl city market places of Mizoram. Vendors were selected on the basis of their location and by the processing methods that were utilized. Samples were collected in triplicates on the 3rd, 5th and 7th days of fermentation, processed in the same container from the same vendor. Before processing for further analysis, triplicate sets of each sample were pooled together. Therefore, three samples from each fermented food product (Tuaither, Bekang and Sa-um) on the 3rd, 5th, and 7th days of fermentation were used for further analysis. All samples were stored at $4{ }^{\circ} \mathrm{C}$ and used immediately for estimating bacterial diversity. 


\subsection{Proximate Compositional Analysis}

A portion of the collected samples was used to obtain the proximate composition of each product at the time of sampling. Various proximate parameters were assessed based on the methods prescribed by the Association of Official Analytical Chemists (AOAC) [20]. Briefly, protein content was determined based on nitrogen content using the micro-Kjeldahl method. Fat content was analyzed using a Soxhlet apparatus with a suitable solvent as prescribed in the AOAC methods. Moisture content and dry biomass was determined by weighing $2 \mathrm{~g}$ of sample, heating it to dryness in an oven at $110^{\circ} \mathrm{C}$ for $2 \mathrm{~h}$ and then weighing the samples again. All of the proximate parameters are reported in AOAC, 2000 standard format as a percentage. Other parameters such as $\mathrm{pH}$, moisture content, total ash content, crude fiber, carbohydrate, and calorific value were also determined according to AOAC methods (AOAC 2016, 20th Edition) [20].

\subsection{DNA Extraction and Amplicon Sequencing}

All samples $(1 \mathrm{~mL})$ were placed in a phosphate-buffer saline solution and centrifuged at $800 \times g$ for $1 \mathrm{~min}$, after which the supernatants were collected. The supernatants collected from each sample were centrifuged again at $11,000 \times g$ for $3 \mathrm{~min}$ to obtain microbial cell pellets. Genomic DNA isolation was performed using a QIAGEN DNeasy Kit according to the manufacturer's instructions (QIAGEN Inc.). The quality and concentration of DNA obtained from each sample was determined spectrophotometrically using a Nanodrop Lite Spectrophotometer (Thermo Scientific, Waltham, MA, USA) and further assessed on a $1 \%$ agarose gel. The obtained high-quality DNA samples were stored at $-20{ }^{\circ} \mathrm{C}$. Extracted DNA was subjected to amplicon library preparation using a Nextera XT index kit (Illumina, San Diego, CA, USA) according to the $16 \mathrm{~S}$ metagenomic sequencing library preparation protocol provided by Illumina. The V3-V4 region of $16 \mathrm{~S}$ rRNA was amplified using the forward primer, 16SrRNAF ( $5^{\prime}$-GCCTACGGGNGGCWGCAG-3'), and reverse primer, 16SrRNAR (5'-ACTACHVGGGTATCTAATCC-3'). The amplicon libraries were purified using AMPure XP beads, quantified on a Qubit Fluorometer, and sequenced on an Illumina MiSeq platform (Illumina, San Diego, USA) to obtain $2 \times 300$ bp paired-end reads. Sequencing was conducted at a commercial sequencing facility (Eurofins, India).

\subsection{Bioinformatics and Statistical Analysis}

Raw sequence reads in FASTQ format were de-multiplexed into each sample based on the sample-specific barcode sequences. High-quality sequences were obtained using Trimmomatic v0.38 after removal of adapter sequences, ambiguous reads, and low quality sequences (reads with more than $10 \%$ quality threshold $(\mathrm{QV})<20$ phred score) [21]. High-quality forward and reverse paired-end reads were merged using FLASH (v1.2.11) software [22]. Further processing of the sequence data was performed using Quantitative Insights Into Microbial Ecology (QIIME) version 1.9.1 [23]. Assignment of operational taxonomic units (OTUs) was based on sequence similarity and selection of the most representative sequence from each of the grouped reads. OTUs were clustered using a 97\% similarity cutoff utilizing uclust software [24] against the Greengene database (version 13-_8) with the "pick_open_reference_otus.py" Qiime script. BLAST analysis (with default e-value) of the OTU reads against the Greengene database was used for taxonomic classification based on the RDP classifier (Version 2.2) algorithm [25]. All downstream analyses, including alpha diversity and compositional analysis were performed using Microbiome Analyst software [26]. Bacterial abundance and diversity analysis based on alpha diversity indices, such as observed species, Shannon index, and Chao1, was conducted using an OTU matrix and performed in QIIME [23]. Multivariate principal component analysis (PCA) was conducted using STAMP software [27]. The distance matrix for the PCA was generated using an unweighted UniFrac approach. OTU significance was determined using an unweighted UniFrac and Cluster Analysis of the Unweighted Pair-Group Method with Arithmetic means (UPGMA). Correspondence analysis (CCA) was conducted to determine the re- 
lationship between nutritional factors and normalized abundances of major taxonomic groups using PAST v3.14 software [28].

\section{Results and Discussion}

\subsection{Proximate Compositional Analysis}

During fermentation, microorganisms convert the chemical constituents of food materials into high value nutrients that improve the flavor and texture of the final fermented food product [29-32]. An assessment of the proximate composition analysis of the three fermented foods examined at three different stages of fermentation (3rd, 5th, and 7th day of fermentation) are presented in Table 1.

Table 1. Proximate composition of fermented bamboo shoots (Tuaither), soybean (Bekang), and pork fat (Sa-um) collected after 3,5 , and 7 days of fermentation.

\begin{tabular}{|c|c|c|c|c|c|c|c|c|c|}
\hline \multirow{3}{*}{$\begin{array}{l}\text { Proximate Parameters } \\
\text { (Weight in \%) }\end{array}$} & \multicolumn{9}{|c|}{ Fermented Food Samples } \\
\hline & \multicolumn{3}{|c|}{ Tuaither } & \multicolumn{3}{|c|}{ Bekang } & \multicolumn{3}{|c|}{ Sa-um } \\
\hline & 3rd D & 5 th D & 7th D & 3rd D & 5th D & 7th D & 3rd D & 5 th D & 7th D \\
\hline Moisture content & 86.8 & 86.4 & 87.6 & 58.3 & 57.1 & 56.4 & 3.8 & 3.8 & 2.5 \\
\hline Total ash content & 1.1 & 1.1 & 1.1 & 2.7 & 2.5 & 1.1 & - & - & - \\
\hline Fat & 1.1 & 0.9 & 1.2 & 4.6 & 5.3 & 5.4 & 90.6 & 94.6 & 95.6 \\
\hline Protein & 2.7 & 3.0 & 2.8 & 19.7 & 19.9 & 18.5 & 1.3 & 1.3 & 1.5 \\
\hline Crude fiber & 3.1 & 2.1 & 2.2 & 10.6 & 2.4 & 2.5 & - & - & - \\
\hline Carbohydrate & 5.2 & 6.5 & 7.9 & 4.1 & 12.8 & 16.2 & 4.2 & 0.2 & 0.3 \\
\hline $\begin{array}{l}\text { Calorific value } \\
\text { (K cals / } 100 \text { gm) }\end{array}$ & 3.97 & 4.19 & 3.98 & 7.20 & 8.36 & 8.23 & 5.89 & 3.99 & 4.04 \\
\hline
\end{tabular}

The fermented food products (Tuaither and Sa-um) exhibited an acidic $\mathrm{pH}$ (4.04 for Tuaither and 4.04 for Sa-um) during the fermentation process. This may be due to the lactic acid produced by the lactic-acid bacteria [33]. The Bekang sample, however, exhibited a slightly basic $\mathrm{pH}$ (7.93). Average moisture content was highest in the bamboo shoot samples $(86.93 \%)$, followed by the soybean samples $(57.26 \%)$, and was lowest in the pork fat samples (3.36\%). A previous study on the proximate composition of Bambusa balcooa (ChingSanei-bi) also reported high moisture content (90.73-91.5\%) [34]. As expected, fat content was highest in the pork fat samples $(93.60 \%)$, followed by the soybean samples $(5.3 \%)$, and was lowest in the bamboo shoot samples (1.06\%). Interestingly, the soybean samples were found to have a higher protein (19.36\%) and carbohydrate content $(11.03 \%)$ than the bamboo shoot and pork fat samples. The lowest protein content was observed in the samples of the bamboo shoots $(2.83 \%)$ and pork fat $(1.36 \%)$. This was also true for the carbohydrate content, which was $6.53 \%$ in the bamboo shoot samples and $1.56 \%$ in the pork fat samples. A low level of crude fiber was detected in the bamboo shoot $(2.46 \%)$ and soybean $(1.56 \%)$ samples, and was undetectable in pork fat samples. A slight increase in protein, carbohydrate, and fat content was observed from the 3rd to 5th day of fermentation; however, it was not a significant increase as the same trend was not found during the latter stage of fermentation (Table 1).

\subsection{Bacterial Diversity}

A total of 93,857 (3rd day), 267,981 (5th day), and 187,190 (7th day) reads were obtained from the fermented bamboo shoot samples, 165,177 (3rd day), 252,177 (5th day), and 259,761 (7th day) for the fermented soybean samples, and, 208,302 (3rd day), 152,718 (5th day) and 126,281 (7th day) for the fermented pork fat samples. A total of 3424 OTUs were identified collectively from all the samples after clustering of all the high-quality reads. The proportion of OTUs in the samples was found to be quite similar, suggesting that the 
data was sufficient to compare bacterial diversity between the different fermented food products. Rarefaction was conducted on the OTU data sets of each of the different foods for each of the sampled time points (Figure 2). Results indicated that the number of reads obtained for all the samples were near saturation, suggesting that a sufficient number of reads had been obtained in the samples to accurately assess bacterial diversity.
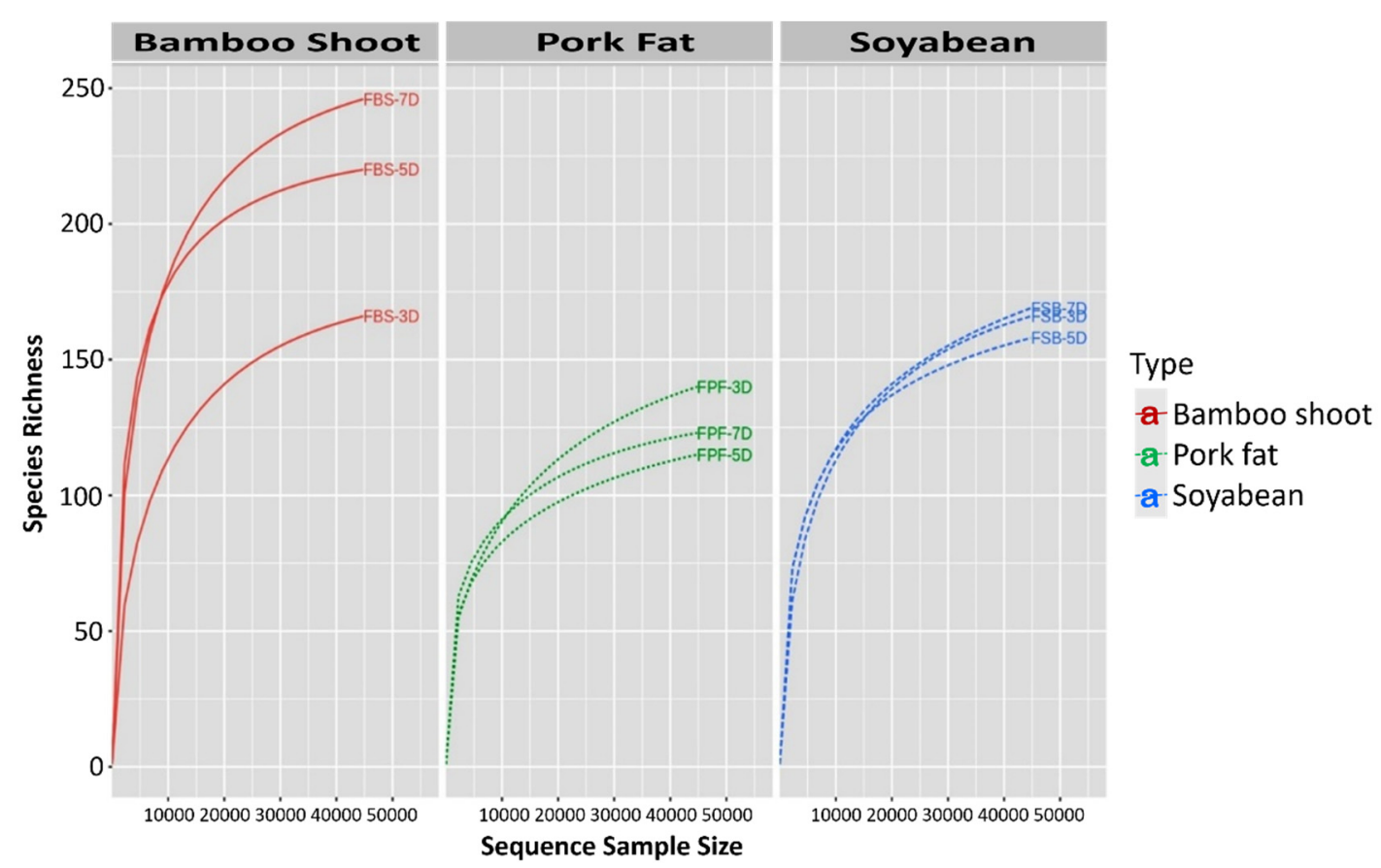

Figure 2. Rarefaction curves for the sequences obtained from fermented bamboo shoots (FBS), soybeans (FSB), and pork fat (FPF) collected at 3, 5, and 7 days of fermentation.

Simpson diversity and Chao1 indices of bacterial diversity (Figure 3) revealed that bamboo shoots (FBS) exhibited the highest level of bacterial diversity, followed by soybean (FSB) samples, while the lowest alpha-diversity was observed in pork fat (FPF) samples. Chao1 and Shannon indices are directly correlated with community diversity. The Shannon index of the FBS samples revealed that samples collected at the 7th day of fermentation had the highest species richness. However, species richness in the soybean (FSB) and pork fat (FPF) samples was found to be more evenly distributed from the 3rd day to the 7th day of the fermentation. 

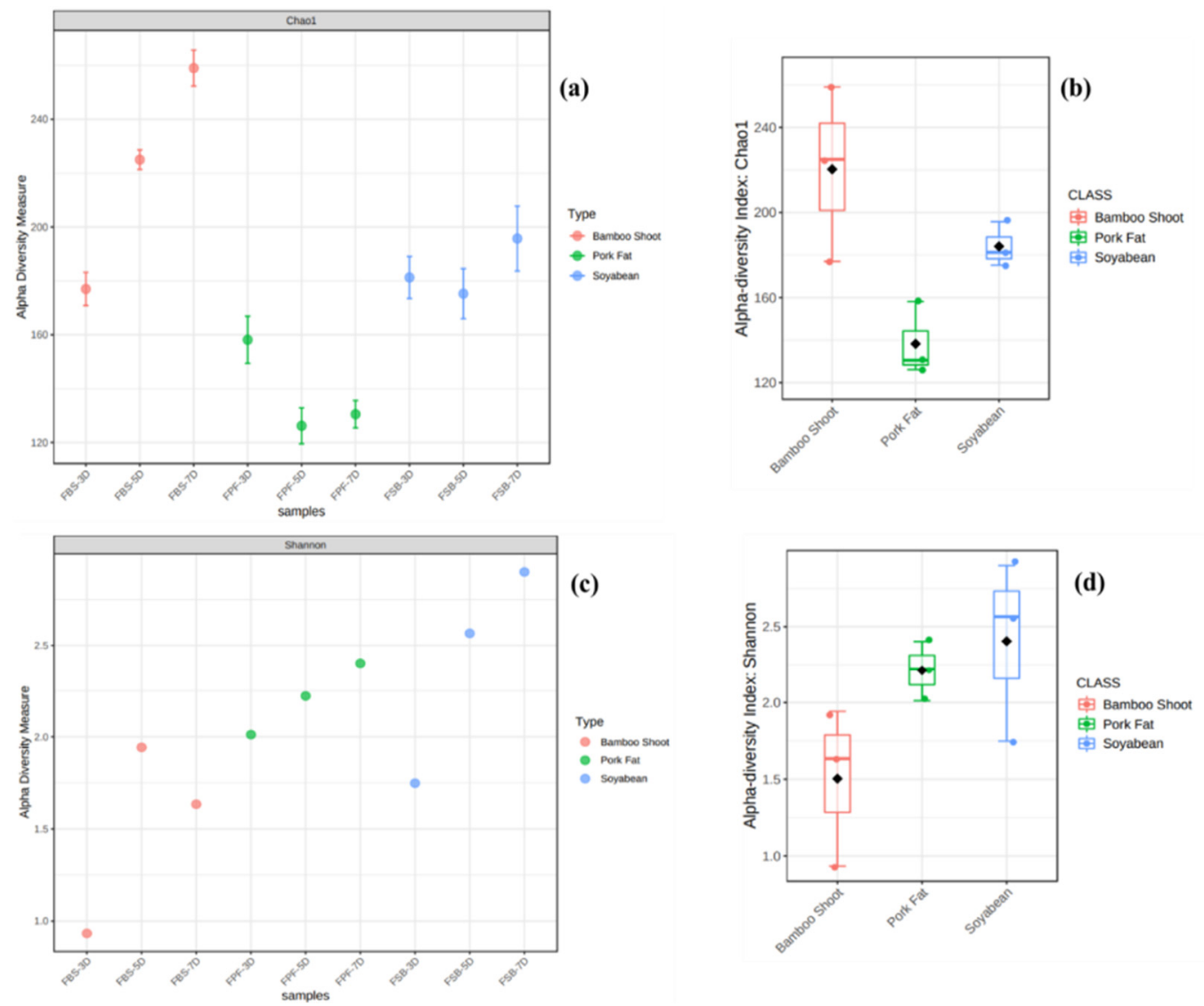

Figure 3. Alpha diversity, Chao-1, and Shannon indices of bacterial diversity in fermented food samples (Bamboo shoots, soybean, and pork fat), (a) and (c) represent the alpha diversity of the three collection dates (3rd, 5th, and 7th day) for each food-type, while b and d represent Chao-1 (b) and Shannon (d) bacterial diversity of the collective samples of each fermented food product. (The samples data was normalized at the depth of the minimum library size, i.e., sample with least reads: FBS-3D; 93,857).

\subsection{Bacterial Community Composition}

All of the fermented food samples possessed a diverse range of bacterial taxa. The relative abundance of the top phyla and genera is shown in Figures 4 and 5, respectively. On the 3rd day of fermentation, at the phylum level, the highest abundance was recorded for Firmicutes (94.99-82.72-92.91\%), Proteobacteria (4.67-15.01-6.82\%), Bacteroidetes (0.13-0.027-0.038\%), Actinobacteria (0.077-2.14-0.18\%), and Verrucomicrobia $(0.023-0.002-0.0049 \%)$ in bamboo shoot (FBS), soybeans (FSB) and pork fat (FPF) samples, respectively. Firmicutes was the most abundant phylum in all samples, exhibiting an average relative abundance $>90.22 \%$. Proteobacteria was the second most abundant phylum in all samples, with an average relative abundance $>8.83 \%$. Similar results for the relative abundance of Firmicutes and Proteobacteria were reported in a recent study of 'zha-chili', a traditional Chinese fermented food [35]. Another study of a fermented vegetable, Suancai, a popular fermented food product in northern China, also reported the highest relative abundance for the bacterial phyla Firmicutes and Proteobacteria [36]. 

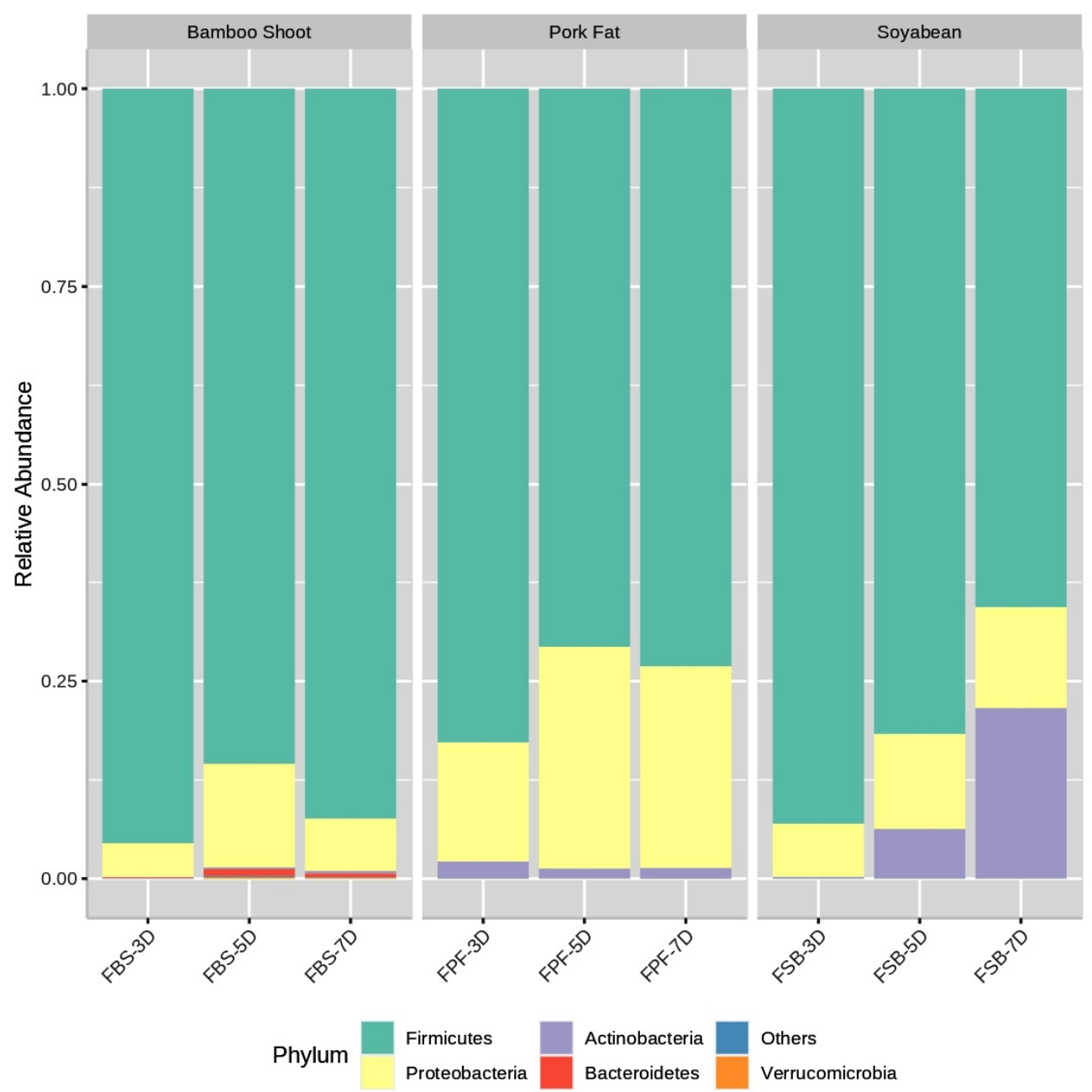

Figure 4. Relative abundance of top bacterial phyla in fermented bamboo shoots (FBS), pork fat (FPF), and soybeans (FSB) samples collected on the 3rd, 5th, and 7th day of fermentation.

Other bacterial phyla were present but at a much lower level of abundance $(<1 \%)$, including Planctomycetes, Fusobacteria, Chloroflexi, Acidobacteria, Nitrospirae, Spirochaetes, Gemmatimonadetes, Synergistetes, Lentisphaerae, Elusimicrobia, and Chlorobi. On the 5th and 7th day of fermentation, the relative abundance of Firmicutes decreased slightly, while Proteobacteria increased in soybean samples (70.85\%). A few other phyla were detected on the 5th and 7th day of fermentation, including Chloroflexi, Fusobacteria, Acidobacteria, Tenericutes, Fibrobacteres, and Caldiserica. An increase in bacterial diversity towards the latter stages of fermentation suggests that these bacterial taxa may play a role in determining the texture and flavor of the final fermented food product. Significant differences were observed at the genus level among all three of the fermented foods, irrespective of the days of fermentation (Figure 5).

Lactobacillus was found with the highest relative abundance (91.64\%) in fermented bamboo shoots. Its relative abundance was lower $(4.81 \%)$ in fermented soybeans, and lowest $(0.042 \%)$ in fermented pork fat. In the case of fermented soybeans, however, Staphylococcus (52.36\%), Bacillus (38.47\%) and Pseudomonas (6.40\%) genera were found to be abundant. Around half of the sequence reads were assigned to OTUs that belong to Staphylococcus in fermented soybeans on the 3rd day of fermentation. Notably, this genus was not detected in the other two fermented food products. In the case of fermented pork fat, Clostridium (72.48\%), Sutterella (12.54\%), and Lactobacillus (4.81\%) were the most abundant genera observed. 


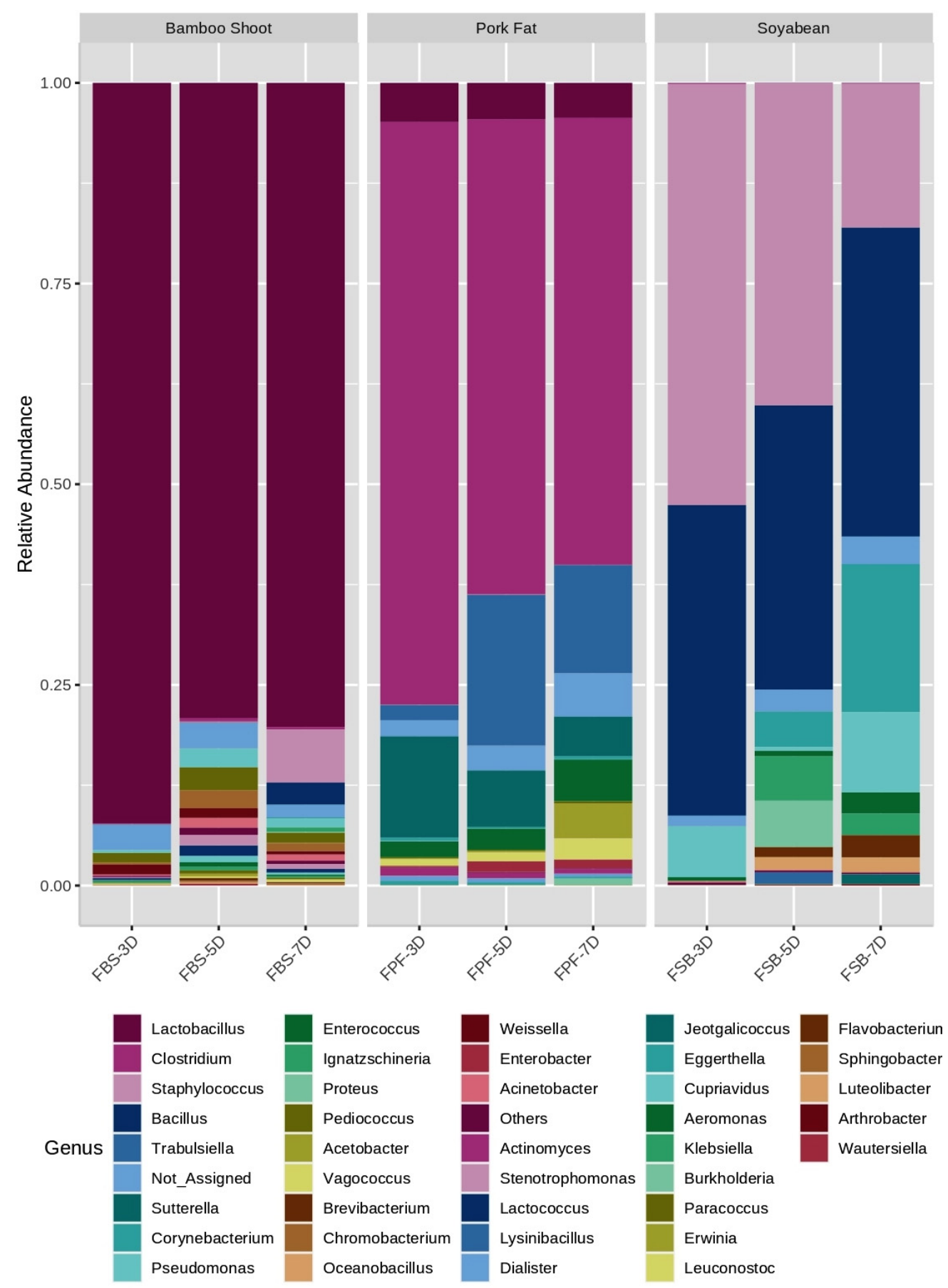

Figure 5. Relative abundance of bacteria at the genus level in fermented bamboo shoots (FBS), pork fat (FPF), and soybean (FSB) on the 3rd, 5th and 7th day of fermentation.

Lactobacillus, Staphylococcus, and Clostridium accounted for more than $60.53 \%$ of the total bacterial reads in all three fermented food products. Lactobacillus species play a significant role in bamboo and lactic acid bacteria have been reported to be the dominant bacterial taxa in several fermented bamboo products [37]. A traditional fermented bamboo shoot product, Khorisa, produced and utilized by the indigenous people of Assam, was reported to possess a variety of actobacilli with potential antimicrobial activity and, thus, high pharmacological value [38]. Studies have shown that Lactobacillus species can produce volatile compounds that enhance the aroma of fermented foods [36]. In addition to Lactobacillus, other bacterial taxa, such as Pediococcus, Enterococcus, Lactococcus, 
Streptococcus and others, can also modify the flavor of original food components and improve the nutritional value of fermented foods $[39,40]$. In the present study, several other lactic acid bacteria and related species, including Pediococcus, Enterococcus, and Lactococcus were found to be present in in fermented bamboo shoot samples at a relative abundance $>1 \%$, while Bacillus, Pseudomonas, and Enterococcus were found in fermented soybean samples. In fermented pork samples, Sutterella, Lactobacillus, Enterococcus, and Trabulsiella were found overall with relatively higher abundances (1.92\% to $13.36 \%)$.

Staphylococcus accounted for $>50 \%$ of the relative abundance in the different samples of the fermented soybean product. The presence of Staphylococcus has been reported in a variety of fermented food products [41]. Staphylococcus and other genera of bacteria have been reported to play a role in the production of synthetic esters in fermented food products [42]. Notably, coagulase negative Staphylococcus species have been reported as the predominant species of bacteria in fermented foods worldwide. Species of Staphylococcus are used as microbial starters in cheese, meat, and soybean fermentation [43]. Importantly, a few species of Staphylococcus are also known to be food borne pathogens for humans and other animals [44]. Therefore, more detailed studies on the Staphylococcus species present in fermented foods using multiple taxonomic approaches is essential to obtain confirmed identification at the species level, especially as their proportion is relatively high in traditional fermented foods that are produced in relatively open environments [45]. Clostridium exhibited the highest relative abundances in the fermented pork fat samples. The prevalence of several enteric bacteria including Clostridiumin traditional fermented foods of North-East India also has been reported previously [46].

\subsection{Comparison of Bacterial Communities during the Fermentation Process}

Beta diversity represents a comparison of diversity among different samples based on the relatedness and differences in the microbial community composition of distantly related samples. The weighted UniFrac distance and un-weighted UniFrac distance were used to conduct a principal coordinate analysis ( $\mathrm{PCOA}$ ) to investigate the variation in microbial species in all samples (Figure 6).

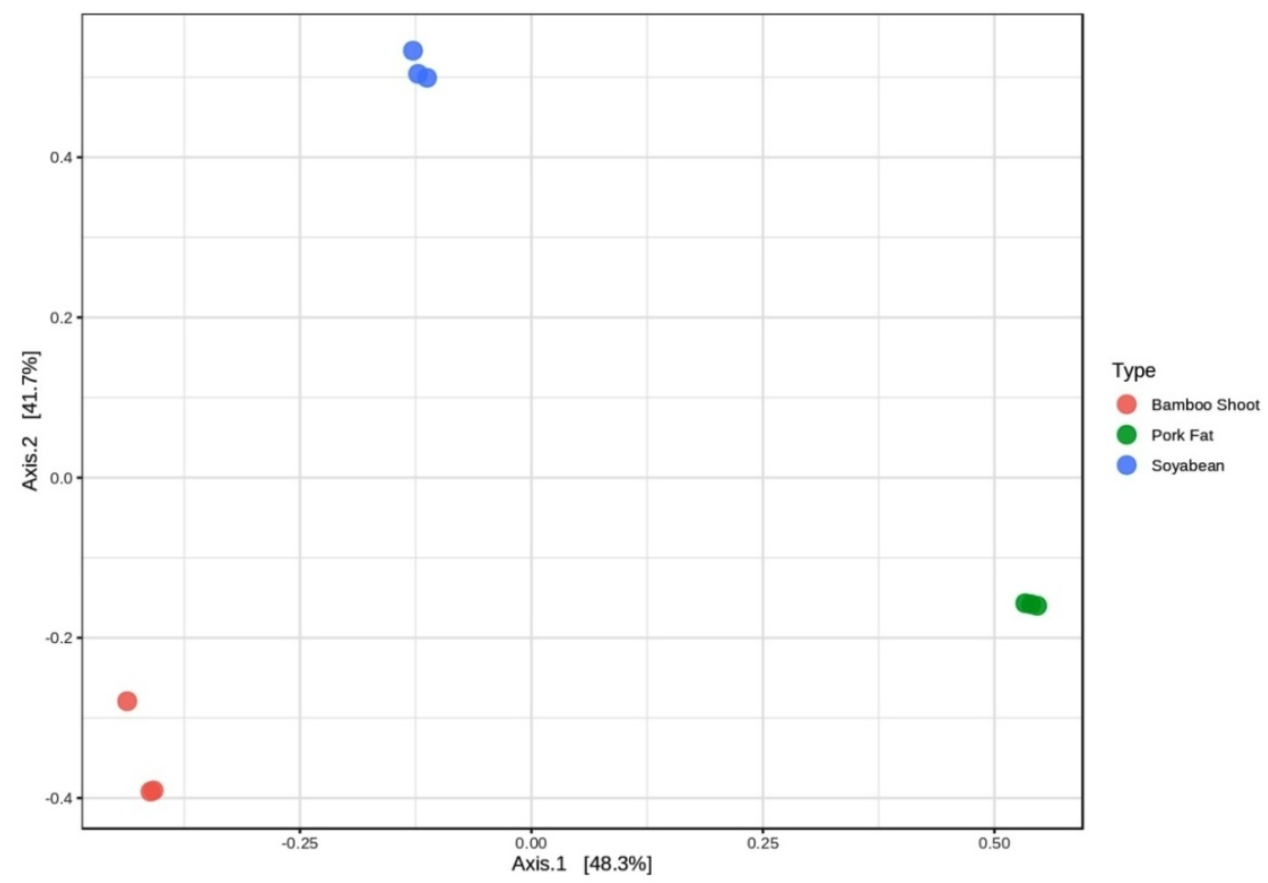

Figure 6. Principal component analysis of bacterial communities in the three different fermented foods (bamboo shoot, soybean, and pork fat). 
Results indicated significant variation in the community composition of the three different food samples. PCoA analysis revealed significant difference in the microbial composition of the different fermented foods. However, each group displayed a similar composition at different stages of the fermentation process (3,5, and 7 days of fermentation). Samples of bamboo shoots, soybean, and pork fat are all greatly separated in the graphs of the PCoA analysis. However, each of the stages of fermentation within each fermented food type clustered close to one another, indicating a similar composition (Figure 6). The first and second principal components accounted for $41.7 \%$ and $48.3 \%$ of the variance among the samples. The obtained values indicate that the three types of fermented foods examined in the study are distantly related to each other in their composition of bacterial genera. A hierarchically clustered heat map analysis based on the bacterial community profile at the genus level is shown in Figure 7.

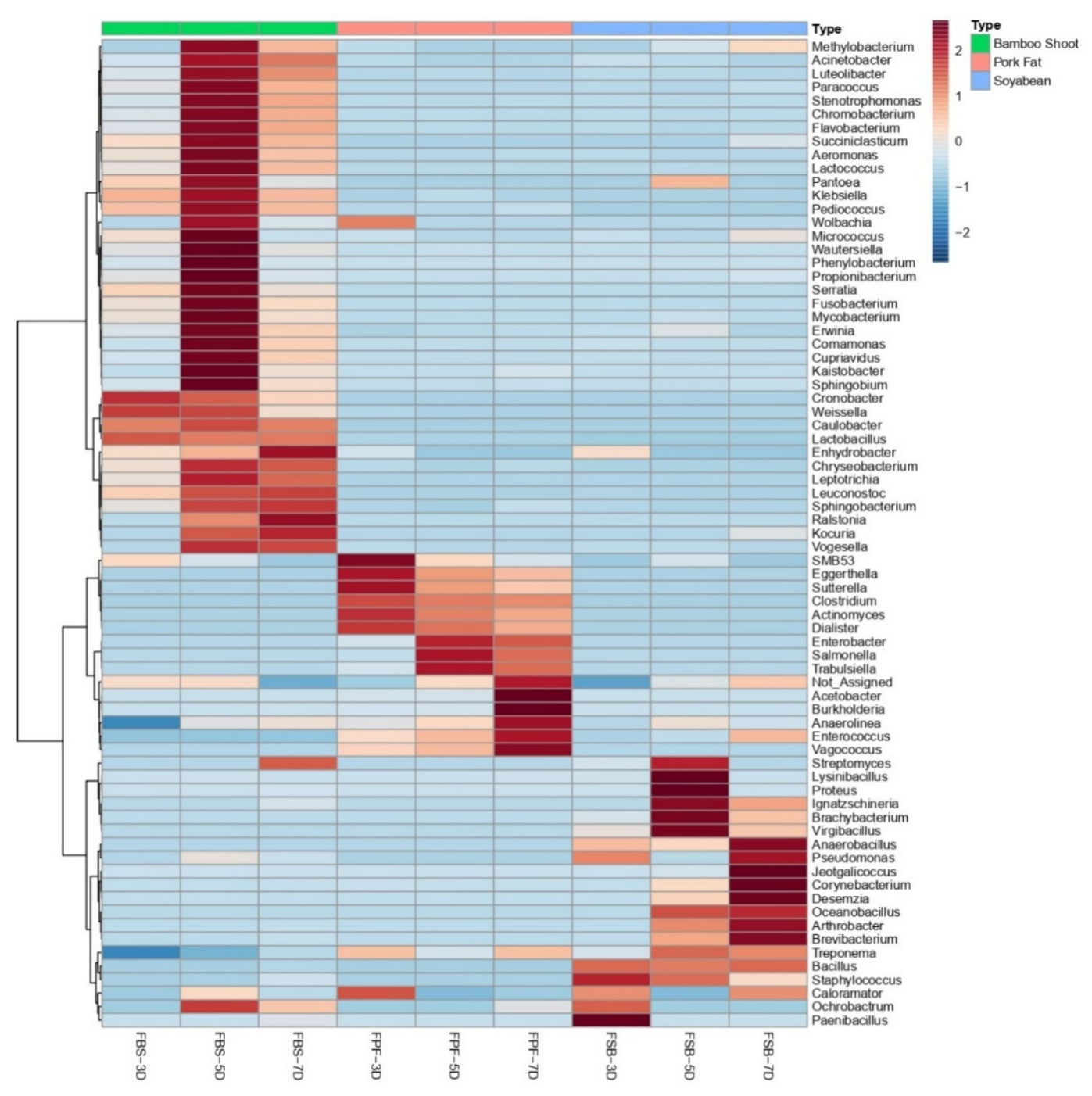

Figure 7. Heat map of bacterial community composition at the genus level of the different fermented food samples: bamboo shoots (FBS), pork fat (FPF), and soybean (FSB) collected at 3, 5, and 7 days of fermentation. Blue to red color intensity indicates a low to high relative abundance.

The dominant phylum in bamboo shoots formed a separate cluster, while the most abundant bacterial phylum in soybean and pork fat samples formed a separate cluster that was again divided into another sub-cluster. The dominant genera present in each food type formed three different distantly-related clusters. Lactobacillus, Staphylococcus, and Clostridium were the most abundant genera in the three types of fermented food samples. 
The microbial composition of the fermented food changes over the course of time and different microbial groups play a functional role in adding nutritional value to the final product [47]. Relative abundance of the top most abundant bacterial genera in the samples of fermented foods collected on the 3rd, 5th, and 7th day of fermentation is given in Table 2.

Table 2. Relative abundance of the top most bacterial genera in day wise samples of the fermented foods.

\begin{tabular}{|c|c|c|c|}
\hline \multicolumn{4}{|c|}{ Fermented Bamboo Shoot (FBS) } \\
\hline Genus & FBS-3D & FBS-5D & FBS-7D \\
\hline Lactobacillus sp. & 91.64 & 77.16 & 78.88 \\
\hline Weissella sp. & 1.27 & 0.0 & 0.0 \\
\hline Pediococcus sp. & 1.17 & 2.80 & 0.0 \\
\hline Pseudomonas sp. & 0.36 & 2.24 & 1.25 \\
\hline Chromobacterium sp. & 0.27 & 2.29 & 0.0 \\
\hline Acinetobacter sp. & 0.0 & 1.35 & 1.14 \\
\hline Corynebacterium sp. & 0.0 & 0.0 & 6.58 \\
\hline Sphingobacterium sp. & 0.0 & 0.0 & 2.74 \\
\hline Unclassified & 3.13 & 2.28 & 2.27 \\
\hline Others & 1.86 & 11.58 & 7.11 \\
\hline \multicolumn{4}{|c|}{ Fermented Pork Fats (FPF) } \\
\hline Genus & FPF-3D & FPF-5D & FPF-7D \\
\hline Clostridium sp. & 72.48 & 59.48 & 55.40 \\
\hline Sutterella sp. & 12.54 & 7.01 & 4.85 \\
\hline Lactobacillus sp. & 4.81 & 4.44 & 4.41 \\
\hline Enterococcus sp. & 1.92 & 2.67 & 5.28 \\
\hline Trabulsiella sp. & 1.81 & 18.45 & 13.36 \\
\hline Unclassified sp. & 2.07 & 3.26 & 5.24 \\
\hline Others & 3.17 & 4.67 & 11.43 \\
\hline \multicolumn{4}{|c|}{ Fermented Soybean (FSB) } \\
\hline Genus & FSB-3D & FSB-5D & FSB-7D \\
\hline Staphylococcus sp. & 52.36 & 39.48 & 17.90 \\
\hline Bacillus sp. & 38.47 & 35.56 & 37.87 \\
\hline Pseudomonas sp. & 6.40 & 0.0 & 9.67 \\
\hline Enterococcus sp. & 0.47 & 0.0 & 0.0 \\
\hline Paenibacillus sp. & 0.19 & 0.0 & 0.0 \\
\hline Proteus sp. & 0.0 & 5.89 & 0.0 \\
\hline Ignatzschineria sp. & 0.0 & 5.49 & 0.0 \\
\hline Corynebacterium sp. & 0.0 & 4.35 & 18.13 \\
\hline Brevibacterium sp. & 0.0 & 0.0 & 2.77 \\
\hline Unclassified & 1.12 & 2.98 & 3.61 \\
\hline Others & 0.95 & 6.23 & 10.02 \\
\hline
\end{tabular}

The bacterial composition of top genera in fermented bamboo shoots on the 3rd, 5th, and 7th day of fermentation is summarized in Table 2. The 3rd day sample of bamboo shoots (FBS_3D) exhibited a high abundance of Lactobacillus (91.64\%) and a much smaller 
proportion of a few other genera, such as Weissella (1.27\%) and Pediococcus (1.17\%). The abundance of Lactobacillus in bamboo shoots, however, decreased on the 5th (FBS_5D; 77.165\%) and 7th (FBS_7D; 78.88\%) days of fermentation, while the abundance of Pediococcus increased to $2.8 \%$. Differentiation of lactobacilli (LAB), such as Weissella, Pediococcus, and Lactobacillus, to species and strain levels require more definitive methods. Their rapid and accurate identification is of the utmost importance in food microbiology [48]. LAB species, such as Pediococcus, possess intriguing attributes, such as exopolysaccharides production, and the ability to enhance the aroma of fermented foods and increase the level of lactic acid present in the fermented product [49]. Interestingly, a few of the genera, such as Chromobacterium (2.29\%), Pseudomonas (2.24\%), Acinetobacter $(1.35 \%)$, Corynebacterium $(6.58 \%)$, and Sphingobacterium $(2.74 \%)$ exhibited a sudden increase in their relative abundance in fermented bamboo shoots on the 7th day of fermentation.

Samples of fermented soybeans collected on the 3rd day of fermentation (FSB_3D) exhibited a high relative abundance of Staphylococcus (52.36\%) and Bacillus (38.47\%), as well as other genera, including Pseudomonas (6.40\%), Enterococcus $(0.47 \%)$, and Paenibacillus $(0.19 \%)$ with a much lower level of relative abundance. Notably, the relative abundance of Staphylococcus decreased continuously (52.36\% to $17.90 \%$ ) from the 3rd day to the 7th day of fermentation, however, the relative abundance of Bacillus remained relatively constant (38.47-35.56-37.87\%). Soybean foods are generally fermented by Bacillus spp. and impart a characteristic stickiness to the final product. The microbial composition of a variety of fermented soybean foods such as natto (from Japan) and kinema (from Nepal and North-East India) have been reported [50]. In our present study, genera other than Bacillus, such as Proteus (5.89\%), Ignatzschineria (5.49\%), and Clostridium (4.35\%) were found to increase in relative abundance in samples collected after the 5th day of fermentation (FSB_5D). Clostridium (18.13\%), Pseudomonas (9.67\%), and Brevibacterium $(2.77 \%)$ exhibited the greatest increase in relative abundance on the 7 th day of fermentation. This was especially true for Clostridium, which increased from approximately $0.05 \%$ on the 3 rd day of fermentation to $4.35 \%$ on the 5 th day, and more than $18 \%$ on the 7 th day of fermentation.

High populations of Clostridium have many potential consequences that may be harmful to consumers. Therefore, it is important to consider the timing of the natural fermentation of foods. Clostridium (72.48\%), Sutterella (12.54\%), Lactobacillus (4.81\%), Enterococcus $(1.92 \%)$ and Trabulsiella $(1.81 \%)$ were the most abundant genera in pork fat samples on the 3rd day of fermentation (FPF_3D). The relative abundance of Clostridium, however, decreased by approximately $13 \%$ on the 5 th day of fermentation (FPF_5D) and by an additional $4.08 \%$ on the 7th day of fermentation (FPF_7D). Clostridium and a few other foodborne bacterial pathogens recognized by the World Health Organization (WHO) have been previously identified in Indian fermented foods, including pork fat, using MiSeq amplicon sequencing [46]. In the present study, other genera, such as Trabulsiella (18.45\%), Sutterella (7.01\%), Lactobacillus (4.44\%), and Enterococcus (2.67\%) did not exhibit significant variation in relative abundance in any of the three food types during the fermentation process. The distribution of bacterial species in the ethnic fermented food samples native to Mizoram only exhibited variation in the relative abundance of the few dominant genera. These results suggest that the type of raw food material and the fermentation environment in these regions may impact bacterial richness but not the diversity. Similar findings have been previously reported in other types of fermented food products [51-53].

\subsection{Correlation Analysis of Nutritional Parameters with Bacterial Diversity}

Canonical correlation analysis (CCA) was conducted to evaluate the relationship between bacterial members (at the level of phylum and genus) and the proximate composition of the food materials (Figure 8). Results of the CCA indicated that Lactobacilli were positively correlated with fermented bamboo shoot samples, Staphylococcus was correlated with fermented soybean samples, and Clostridium was correlated with fermented pork 
fat samples. Staphylococcus was positively correlated in soybean samples with protein, carbohydrate and crude fiber content. Determining the correlation of microbial members with food components is important for understanding the microbial communities of related food samples and can lead to the design of synthetic microbial consortia for optimum fermentation of specific food types [54].
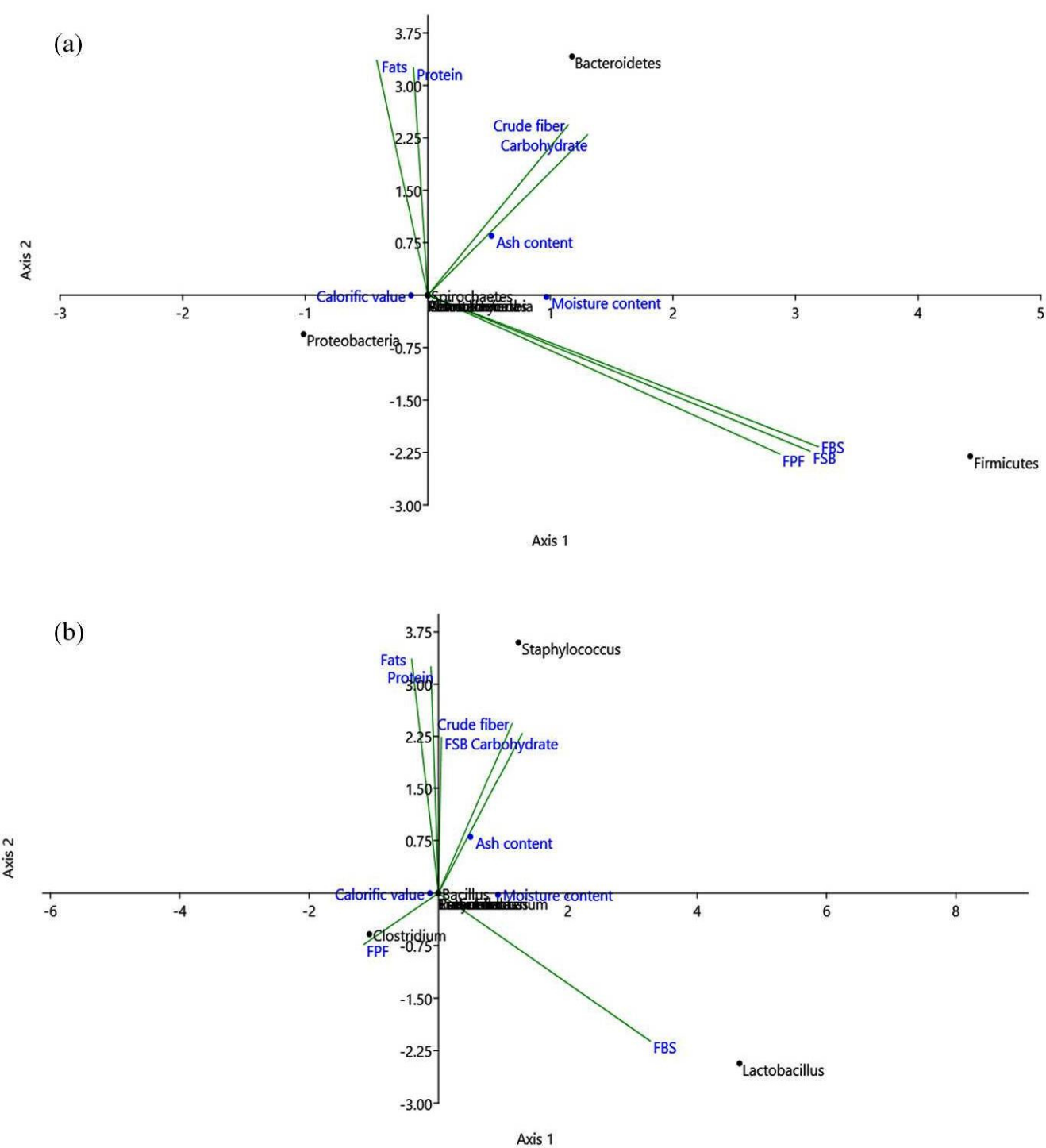

Figure 8. Triplot illustrating the results of the Canonical Correspondence Analysis (CCA) of the relative abundance of bacterial phyla (a), genera $(\mathbf{b})$ and compositional attributes of the fermented food samples. Fermented bamboo shoots (FBS), fermented soybeans (FSB), and fermented pork fat (FPF).

\section{Conclusions}

The consumption of traditionally fermented food has a beneficial impact on consumer health due to the of presence beneficial microbial taxa. The present study examines the proximate composition and bacterial diversity of three different traditional fermented foods native to the Mizoram state of India. Samples collected at three different times (3rd, 5 th, and 7th day) during the fermentation process were analyzed. Proximate composition analysis revealed the differences in the proximate content, such as fat, protein, and moisture content among the three different types of samples. Bacterial diversity analysis revealed that Firmicutes and Proteobacteria had the highest relative abundance in all the samples. 
However, variation in the relative abundances was observed at the genus level. Lactobacillus, Staphylococcus, and Clostridium showed the highest dominance in fermented bamboo shoots (Tuaither), fermented soybeans (Bekang), and fermented pork fat (Sa-um) respectively. Other genera, such as Weissella, Bacillus, Lactococcus, and Pseudomonas, were also found to be present in most of the samples. On the 3rd day, the highest dominance was observed for Lactobacillus, Staphylococcus, and Clostridium respectively in fermented bamboo shoots (Tuaither), fermented soybeans (Bekang), and fermented pork fat (Sa-um) sample. However, a decrease in their abundance was seen towards the 7th day of fermentation. In addition, various other bacterial taxa were found in each of the fermented samples, showing a presence of high bacterial diversity in the fermented products. A correlative analysis exhibited a positive correlation of a few of bacterial with the proximate content of the food samples. This study is the first report on the bacterial diversity of the traditional fermented products of Mizoram using metagenomics analysis, and has revealed important information on bacterial community structure and dominance of major bacteria associated with different traditionally fermented foods. Therefore, the present study could be helpful for establishing more comprehensive investigations into the identification of indigenous bacteria with potential probiotic properties, and enable the discovery of more health benefits in traditional fermented foods, using both culture-independent and -dependent approaches.

Author Contributions: Conceptualization, B.P.S., G.T.M., K.U., E.L., P.D. wrote-original draft preparation, P.D., G.T.M.; drafting manuscript and data analysis, B.P.S. and K.U.; critically revised the final version, E.F.A., G.T.M. made intellectual contribution in drafting the manuscript, A.H., A.-B.F.A.-A., E.F.A., B.P.S., E.L., G.S., K.U. reviewed the manuscript. All authors have read and agreed to the published version of the manuscript.

Funding: The work was carried out under financial support from a joint international grant from the Department of Science and Technology (DST) of the Government of India; project number C/1756/IFD/2019-20, and the Russian Science Foundation, project number 19-46-02004. The authors would like to extend their sincere appreciation to the Researchers Supporting Project Number (RSP2021/356), King Saud University, Riyadh, Saudi Arabia for covering APC.

Institutional Review Board Statement: Not applicable.

Informed Consent Statement: Not applicable.

Data Availability Statement: All data generated during this study are included in this article.

Acknowledgments: B.P.S. and K.U. are thankful to the Department of Science and Technology (DST), New Delhi, Government of India for financial support. The authors are thankful to the ViceChancellor of Mizoram University, Mizoram, India and NIFTEM, Sonepat, India for their continuous support. The authors would like to extend their sincere appreciation to the Researchers Supporting Project Number (RSP-2021/356), King Saud University, Riyadh, Saudi Arabia.

Conflicts of Interest: Authors declare no conflict of interest.

\section{References}

1. Tsafrakidou, P.; Michaelidou, A.M.; Biliaderis, C.G. Fermented Cereal-based Products: Nutritional Aspects, Possible Impact on Gut Microbiota and Health Implications. Foods 2020, 9, 734. [CrossRef]

2. Mathara, J.M.; Schillinger, U.; Kutima, P.M.; Mbugua, S.K.; Holzapfel, W.H. Isolation, identification and characterization of the dominant microorganisms of kulenaoto: The Maasai traditional fermented milk in Kenya. Int. J. Food Microbiol. 2004, 94, 269-278. [CrossRef]

3. Mokoena, M.P.; Mutanda, T.; Olaniran, A.O. Perspectives on the probiotic potential of lactic acid bacteria from African traditional fermented foods and beverages. Food Nutr. Res. 2016, 60, 29630. [CrossRef]

4. Caplice, E.; Fitzgerald, G.F. Food fermentations: Role of microorganisms in food production and preservation. Int. J. Food Microbiol. 1999, 50, 131-149. [CrossRef]

5. Silvestri, G.; Santarelli, S.; Aquilanti, L.; Beccaceci, A.; Osimani, A.; Tonucci, F.; Clementi, F. Investigation of the microbial ecology of Ciauscolo, a traditional Italian salami, by culture-dependent techniques and PCR-DGGE. Meat Sci. 2007, 77, 413-423. [CrossRef] 
6. Kim, T.W.; Lee, J.H.; Kim, S.E.; Park, M.H.; Chang, H.C.; Kim, H.Y. Analysis of microbial communities in doenjang, a Korean fermented soybean paste, using nested PCR-denaturing gradient gel electrophoresis. Int. J. Food Microbiol. 2009, 131, $265-271$. [CrossRef]

7. Sakamoto, N.; Tanaka, S.; Sonomoto, K.; Nakayama, J. 16S rRNApyrosequencing-based investigation of the bacterial community in nukadoko, a pickling bed of fermented rice bran. Int. J. Food Microbiol. 2011, 144, 352-359. [CrossRef] [PubMed]

8. Mehetre, G.T.; Paranjpe, A.S.; Dastager, S.G.; Dharne, M.S. Complete metagenome sequencing based bacterial diversity and functional insights from basaltic hot spring of Unkeshwar, Maharashtra, India. Genom. Data 2016, 7, 140-143. [CrossRef] [PubMed]

9. Cao, Y.; Fanning, S.; Proos, S.; Jordan, K.; Srikumar, S. A review on the applications of next generation sequencing technologies as applied to food-related microbiome studies. Front. Microbiol. 2017, 8, 1829. [CrossRef] [PubMed]

10. Jung, J.Y.; Lee, S.H.; Kim, J.M.; Park, M.S.; Bae, J.W.; Hahn, Y.; Madsen, E.L.; Jeon, C.O. Metagenomic analysis of Kimchi, a traditional Korean fermented food. Appl. Environ. Microbiol. 2011, 77, 2264-2274. [CrossRef] [PubMed]

11. Nalbantoglu, U.; Caker, A.; Dogan, H.; Abaci, N.; Ustek, D.; Sayood, K.; Can, H. Metagenomic analysis of the microbial community in kefir grains. Food Microbiol. 2014, 41, 42-51. [CrossRef]

12. Hong, X.; Chen, J.; Liu, L. Metagenomic sequencing reveals the relationship between microbiota composition and quality of Chinese Rice Wine. Sci. Rep. 2016, 6, 26621. [CrossRef]

13. Tamang, J.P.; Tamanag, B.; Schillinger, U.; Guigas, C.; Holzapfel, W.H. Functional properties of lactic acid bacteria isolated from ethnic fermented vegetables of the Himalayas. Int. J. Food Microbiol. 2009, 135, 28-33. [CrossRef] [PubMed]

14. Nongdam, P. Traditional fermented bamboo shoot foods of North-East India and their characteristics natural microbial flora. In Proceedings of the 10th World Bamboo Congress, Damyeng, Korea, 17-22 September 2015.

15. Lalthanpui, P.B.; Lalruatfela, B.; Zoramdinthara; Lalthanzara, H. Traditional food processing techniques of the Mizo people of Northeast India. Sci. Viss. 2015, 15, 39-45.

16. Marco, M.L.; Heeney, D.; Binda, S.; Cifelli, C.J.; Cotter, P.D.; Foligné, B.; Gänzle, M.; Kort, R.; Pasin, G.; Pihlanto, A.; et al. Health benefits of fermented foods: Microbiota and beyond. Curr. Opin. Biotechnol. 2017, 44, 94-102. [CrossRef] [PubMed]

17. Das, A.J.; Deka, S.C. Fermented foods and beverages of the North-East India. Int. Food Res. J. 2012, $19,377$.

18. Rawat, K.; Kumari, A.; Kumar, S.; Kumar, R.; Gehlot, R. Traditional fermented products of India. Int. J. Curr. Microbiol. App. Sci. 2018, 7, 1873-1883. [CrossRef]

19. Tamang, J.P.; Tamang, N.; Thapa, S.; Dewan, S.; Tamang, B.; Yonzan, H.; Rai, A.K.; Chettri, R.; Chakrabarty, J.; Kharel, N. Microorganisms and nutritional value of ethnic fermented foods and alcoholic beverages of North East India. Indian J. Trad. Know. $2012,11,7-25$.

20. Association of Official Analytical Chemists (AOAC). Official Methods of Analysis, 20th ed.; AOAC International: Gaithersburg, MD, USA, 2016.

21. Bolger, A.M.; Lohse, M.; Usadel, B. Trimmomatic: A flexible trimmer for Illumina sequence data. Bioinformatics 2014, 30, 2114-2120. [CrossRef]

22. Magoč, T.; Salzberg, S.L. FLASH: Fast length adjustment of short reads to improve genome assemblies. Bioinformatics 2011, 27, 2957-2963. [CrossRef] [PubMed]

23. Caporaso, J.G.; Kuczynski, J.; Stombaugh, J.K.; Bittinger, K.; Bushman, F.D.; Costello, E.K.; Fierer, N.; Peña, A.G.; Goodrich, J.K.; Gordon, J.I.; et al. QIIME allows analysis of high-throughput community sequencing data. Nat. Methods 2010, 7, 335-336. [CrossRef]

24. Edgar, R.C. Search and clustering orders of magnitude faster than BLAST. Bioinformatics 2010, 26, 2460-2461. [CrossRef] [PubMed]

25. Wang, Q.; Garrity, G.M.; Tiedje, J.M.; Cole, J.R. Naive Bayesian classifier for rapid assignment of rRNA sequences into the new bacterial taxonomy. Appl. Environ. Microbiol. 2007, 73, 5261-5267. [CrossRef] [PubMed]

26. Dhariwal, A.; Chong, J.; Habib, S.; King, I.L.; Agellon, L.B.; Xia, J. Microbiome Analyst: A web-based tool for comprehensive statistical, visual and meta-analysis of microbiome data. Nucleic. Acids. Res. 2017, 45, 180-188. [CrossRef] [PubMed]

27. Parks, D.H.; Tyson, G.W.; Hugenholtz, P.; Beiko, R.G. STAMP: Statistical analysis of taxonomic and functional profiles. Bioinformatics 2014, 30, 3123-3124. [CrossRef]

28. Hammer, O.; Harper, D.A.T.; Ryan, P. PAST: Paleontological statistics software package for education and data analysis. Palaeontol. Electron. 2001, 4, 1-9.

29. McFeeters, R.F. Fermentation microorganisms and flavor changes in fermented foods. J. Food Sci. 2004, 69, 2002-2004. [CrossRef]

30. Sharma, R.; Garg, P.; Kumar, P.; Bhatia, S.K.; Kulshrestha, S. Microbial fermentation and its role in quality improvement of fermented foods. Fermentation 2020, 6, 106. [CrossRef]

31. Anal, A.K. Quality ingredients and safety concerns for traditional fermented foods and beverages from Asia: A Review. Fermentation 2019, 5, 8. [CrossRef]

32. Hu, Y.Y.; Wang, H.; Kong, B.H.; Wang, Y.; Chen, Q. The succession and correlation of the bacterial community and flavour characteristics of Harbin dry sausages during fermentation. LWT 2021, 138, 110689. [CrossRef]

33. Mugula, J.K.; Narvhus, J.A.; Sørhaug, T. Use of starter cultures of lactic acid bacteria and yeasts in the preparation of togwa, a Tanzanian fermented food. Int. J. Food Microbiol. 2003, 83, 307-318. [CrossRef] 
34. Singh, H.D.; Singh, S.A.; Singh, N.R.; Singh, R. Biochemical composition of Soibum-A fermented bamboo shoot and its dynamics during fermentation in real time model. In Proceedings of the 9th International Conference on Food Engineering and Biotechnology, Bangkok, Thailand, 28-29 May 2011; Volume 9, pp. 11-18.

35. Cai, W.; Tang, F.; Wang, Y.; Zhang, Z.; Xue, Y.; Zhao, X.; Guo, Z.; Shan, C. Bacterial diversity and flavor profile of Zha-Chili, a traditional fermented food in China. Food Res. Int. 2021, 141, 110112. [CrossRef]

36. He, Z.; Chen, H.; Wang, X.; Lin, X.; Ji, C.; Li, S.; Liang, H. Effects of different temperatures on bacterial diversity and volatile flavor compounds during the fermentation of suancai, a traditional fermented vegetable food from northeastern China. $L W T$ 2020, 118, 108773. [CrossRef]

37. Sonar, N.R.; Halami, P.M. Phenotypic identification and technological attributes of native lactic acid bacteria present in fermented bamboo shoot products from North-East India. J. Food Sci. Technol. 2014, 51, 4143-4148. [CrossRef] [PubMed]

38. Badwaik, L.S.; Borah, P.K.; Deka, S.C. Production and Purification of Anti-Bacterial Biometabolite from Wild-Type Lactobacillus, Isolated from Fermented Bamboo Shoot: Future Suggestions and a Proposed System for Secondary Metabolite Onsite Recovery during Continuous Fermentation. Appl. Biochem. Biotechnol. 2015, 175, 1915-1925. [CrossRef] [PubMed]

39. Stiles, M.E.; Holzapfel, W.H. Lactic acid bacteria of foods and their current taxonomy. Int. J. Food Microbiol. 1997, 36, 1-29. [CrossRef]

40. Salminen, S.; von Wright, A.; Ouwehand, A. Lactic Acid Bacteria: Microbiological and Functional Aspects, 3rd ed.; CRC: New York, NY, USA, 2004.

41. Majumdar, R.K.; Gupta, S. Isolation, identification and characterization of Staphylococcus sp. from Indian ethnic fermented fish product. Lett. Appl. Microbiol. 2020, 71, 359-368. [CrossRef]

42. Hasan, F.; Shah, A.A.; Javed, S.; Hameed, A. Industrial applications of microbial lipases. Enzyme Microb. Technol. 2006, 39, $235-251$. [CrossRef]

43. Heo, S.; Lee, J.H.; Jeong, D.W. Food-derived coagulase-negative Staphylococcus as starter cultures for fermented foods. Food Sci. Biotechnol. 2020, 29, 1023-1035. [CrossRef]

44. Fetsch, A.; Johler, S. Staphylococcus aureus as a foodborne pathogen. Curr. Clin. Microbiol. Rep. 2018, 5, 88-96. [CrossRef]

45. Arora, M.; Baldi, A. Selective identification and characterization of potential probiotic strains: A review on comprehensive polyphasic approach. Appl. Clin. Res. Clin. Trials Regul. Aff. 2017, 4, 60-76. [CrossRef]

46. Keisam, S.; Tuikhar, N.; Ahmed, G.; Jeyaram, K. Toxigenic and pathogenic potential of enteric bacterial pathogens prevalent in the traditional fermented foods marketed in the Northeast region of India. Int. J. Food Microbiol. 2019, 296, 21-30. [CrossRef] [PubMed]

47. Zang, J.; Xu, Y.; Xia, W.; Yu, D.; Gao, P.; Jiang, Q.; Yang, F. Dynamics and diversity of microbial community succession during fermentation of Suanyu, a Chinese traditional fermented fish, determined by high throughput sequencing. Food Res. Intern. 2018, 111, 565-573. [CrossRef] [PubMed]

48. Adesulu-Dahunsi, A.T.; Sanni, A.I.; Jeyaram, K. Rapid differentiation among Lactobacillus, Pediococcus and Weissella species from some Nigerian indigenous fermented foods. LWT 2017, 77, 39-44. [CrossRef]

49. Adesulu-Dahunsi, A.T.; Sanni, A.I.; Jeyaram, K. Diversity and technological characterization of Pediococcuspentosaceus strains isolated from Nigerian traditional fermented foods. LWT 2021, 140, 110697. [CrossRef]

50. Tamang, J.P.; Watanabe, K.; Holzapfel, W.H. Diversity of microorganisms in global fermented foods and beverages. Front. Microbiol. 2016, 7, 377. [CrossRef] [PubMed]

51. Liang, R.; Huang, J.; Wu, X.; Fan, J.; Xu, Y.; Wu, C.; Jin, Y.; Zhou, R. Effect of raw material and starters on the metabolite constituents and microbial community diversity of fermented soy sauce. J. Sci. Food Agri. 2019, 99, 5687-5695. [CrossRef]

52. Leech, J.; Cabrera-Rubio, R.; Walsh, A.M.; Macori, G.; Walsh, C.J.; Barton, W.; Finnegan, L.; Crispie, F.; O'Sullivan, O.; Claesson, M.J.; et al. Fermented-Food Metagenomics Reveals Substrate-Associated Differences in Taxonomy and Health-Associated and Antibiotic Resistance Determinants. Msystems 2020, 5, e00522-20. [CrossRef]

53. Fang, G.Y.; Chai, L.J.; Zhong, X.Z.; Jiang, Y.J. Deciphering the succession patterns of bacterial community and their correlations with environmental factors and flavor compounds during the fermentation of Zhejiang rosy vinegar. Int. J. Food Microbiol. 2021, 341, 109070. [CrossRef]

54. Parente, E.; Zotta, T.; Faust, K.; De Filippis, F.; Ercolini, D. Structure of association networks in food bacterial communities. Food Microbiol. 2018, 73, 49-60. [CrossRef] 